This is an accepted manuscript of an article published by Taylor \& Francis in Applied

Edonomics on 01 Jul 2018, available online: https://doi.org/10.1080/00036846.2018.1486999

\title{
Analysts herding: when does sentiment matter?
}

\author{
Natividad Blasco ${ }^{\mathrm{a}}$ \\ (University of Zaragoza) \\ Pilar Corredorb. \\ (Public University of Navarre) \\ Elena Ferrerc. \\ (Public University of Navarre)
}

a Department of Accounting and Finance. Faculty of Economics and Business Administration. Gran Vía 2, 50005 Zaragoza, Spain. e-mail: nblasco@unizar.es

b Department of Business Administration. Faculty of Economics and Institute for Advanced Research in Business and Economics (Inarbe), Campus de Arrosadía s/n, 31006 Pamplona, Spain. e-mail: corredorp@unavarra.es

${ }^{c}$ Department of Business Administration. Faculty of Economics and Institute for Advanced Research in Business and Economics (Inarbe), Campus de Arrosadía s/n, 31006 Pamplona, Spain.e-mail elena.ferrer@unavarra.es

Confirmation corresponding author: Natividad Blasco. Department of Accounting and Finance. Faculty of Economics and Business Administration. Gran Vía 2, 50005 Zaragoza, Spain. e-mail: nblasco@unizar.es

\section{Acknowledgment:}

We would like to thank the anonymous referees for their very useful comments and suggestions.

This paper has received financial support from the Spanish Ministry of Economy and Competitiveness (ECO2016-77631-R (AEI/FEDER, UE) and ECO2013-45568R), and the Government of Aragón/European Social Fund (S14/2). 


\title{
Analysts herding: when does sentiment matter?
}

\begin{abstract}
Herding among analysts emerges when analysts give priority to their peers' opinions instead of their own beliefs or information. Some circumstances may enhance or restrain this type of behavior. We postulate that market sentiment is one of them. This paper analyzes the effect that investor sentiment may have on analysts' herding behavior in the UK. Our results suggest that "easy situations" such as analyzing easy-to-value securities and releasing optimistic information at times of high market sentiment clearly reduce herding practices, whereas herding clearly increases in difficult situations when analysts have to release negative information at moments of high investor sentiment.
\end{abstract}

Keywords: Herding, investor sentiment, analyst forecasts, hard-to-value firms, behavioral finance.

JEL codes: G14; D81 


\section{Analysts herding: when does sentiment matter?}

\section{Introduction}

Herding among analysts emerges when analysts think they should give priority to their peers' opinions instead of their own beliefs or information. Besides the usefulness of detecting herding among security analysts, the identification of those situations that enhance or restrain such practices may also be of interest in terms of providing a deep understanding of stock markets and behavioral finance. Presumably, analysts herd when they have doubts about the results of their own analysis, causing them to be attentive to recommendations released by their colleagues. Generally speaking, analysts should analyze fundamentals in order to release their forecasts or recommendations, but there are a number of circumstances which may hamper this analysis. Investor sentiment is one of them. Sentiment is one of the most important drivers of prices, not based on fundamentals, which can make prices deviate from their "rational" equilibrium. Furthermore, according to the popular market saying attributed to Keynes, "Markets can remain irrational longer than you can remain solvent".

The aim of this paper is to analyze the effect that investor sentiment, considered as the global feeling or attitude of investors toward a particular financial market, may have on analysts' herding behavior. However, as investor sentiment is not based on fundamentals, analysts or sophisticated investors and traders may find different levels of difficulty in detecting stocks that are overvalued or undervalued depending on the type of asset they are dealing with. The degree of difficulty in analyzing a particular firm can make its stock prices more or less sensitive to market sentiment and can make analysts more prone, or not, to herd. For this reason, in order to develop the argument of the paper, we initially test the existence of mimetic behavior by analysts assessing stocks listed on the UK market and then we test whether investor sentiment affects such behavior. The effect of sentiment on herding behavior has not yet been studied in depth. To extend this line of research further, we also want to test whether sentiment is more likely to affect herding when analysts face difficult situations that can generate or accentuate their feeling of risk, which they consider, may jeopardize their professional prestige or promotion prospects. In other words, at moments when they forecast hard to value stocks and/or their information about a company results in an assessment or forecast inconsistent with the general investor sentiment 
(basically a negative recommendation or forecast when investor sentiment is highly positive but also a positive forecast when investor sentiment is highly negative).

The contribution of this paper is twofold. First, the existence of herding among analysts in the UK market has to date been little explored. Given that the UK stock market is the most important Anglo-Saxon market in Europe and one of the most relevant financial markets worldwide, this gap needs to be filled. Second, and more importantly, investor sentiment is introduced as a new explanatory element in the analysis. This sentiment variable is shown to affect analysts' optimistic bias and, to the best of our knowledge, it has not hitherto been considered in the analysis of herding. Given the behavioral connotation of both herding and investor sentiment, we think that sentiment may largely explain herding behavior, at least under specific circumstances or situations that make fundamental assessment more difficult.

The rest of the paper is organized as follows: section 2 develops the theoretical framework and testable hypotheses, section 3 describes the database and the construction of the study variables, section 4 contains the methodology applied and an analysis of the aim of study. Finally, section 5 outlines the main conclusions of the study.

\section{2.-Theoretical framework and testable hypothesis}

Analysts gather private and public information about firms playing an important role in financial markets as information intermediaries. Their reports can help investors in their decision-making process (Ke and $\mathrm{Yu}, 2009$ ) thus reducing the information asymmetry that exists between the firm and its shareholders and between potential buyers and sellers of shares.

Previous analysis has shown the importance of analysts' reports (Givoly and Lakonishok (1984), Fredericksons and Miller (2004), or Ke and Yu (2009), among others). Nevertheless, others have questioned their usefulness due to the existence of an optimistic bias in their forecasts [see, for example, Easterwood and Nutt (1999), Hong and Kubik (2003), Chen and Jiang (2006) or Ramnath et al (2008)]. Given that analysts' need to maintain access to important management-provided information, they may attempt to curry favor with management, making them reluctant to issue sell recommendations or negative opinions (e.g., Francis and Philbrick, 1993, Francis and Soffer, 1997). Sell recommendations may also 
jeopardize the investment banking business of the analysts' employers. Lin and McNichols (1998) or Michaely and Womack (1999), among others, offer evidence consistent with this hypothesis.

As well as their optimistic bias, analysts have also shown herding behavior. This crowd effect or mimetic behavior appears as a result of the agents' risk perception and their emotional ability to control it. Indeed, behavioral finance theory allows some emotional responses to be compatible with agents' optimizing behavior (Elster (1998), Lo (1999), Loewenstein (2000), Peters and Slovic (2000), Thaler (1991), Shefrin (2000)). This behavior is also reflected in financial analysts. Olsen (1996) or De Bondt and Forbes (1999) are some of the first authors to analyze herding behavior among analysts.

Herding occurs when individuals decide to imitate decisions made by other market agents, who they believe to be better informed. In this sort of situation, decision-makers disregard their private information and own beliefs and adopt the line of earlier decisions by others. Following Bikhchandani and Sharma (2000), there are three main herding motives, namely information-based herding (when analysts lack confidence in their private information and there is significant uncertainty about the quality of public information), reputation-based herding (when analysts prefer to get closer to the consensus in order to avoid risking their reputation on the grounds of being personally mistaken) and compensation-based herding (in order to avoid a larger negative pay-off when remuneration depends on how one's performance compares with that of other similar professionals). Given that analysts are considered to be well-informed agents, reputation and compensation based herding seem to be obvious explanations for their imitative behavior. Furthermore, if some stocks offer a higher degree of uncertainty on being analyzed, information-based herding may also occur. Scharfstein and Stein (1990), Roll (1992), Rajan (1994), Trueman (1994), Hirshleifer and Teoh (2003), Brennan and Li (2008) or Maug and Naik (2011) are some of the leading references explaining why reputational or financial gains may induce analysts to get closer to the consensus forecast, ignoring their own beliefs or information.

Analysts finding themselves in this type of situation will tend to keep any extreme views to themselves, adjust their forecast towards the consensus and avoid standing out from their peers. The underlying argument is that collective errors are less detrimental to an analyst's reputation or financial gain than individual errors. In general terms, this feeling is apparent regardless of whether analysts are 
issuing positive or negative recommendations or forecasts. Nevertheless, despite this general logical argument, empirical research in the US market does not offer unanimous results. Whereas some papers such as those by Kim and Pantzalis (2003), Krishnan et al. (2005), Clement and Tse (2005) or Jegadeesh and Kim (2010), among others, find evidence of herding behavior, others do not find general evidence of this type of behavior (Zitzewitz (2001), Chen and Jiang (2006), Bernhardt et al. (2006) or Mensah and Yang (2008)). Outside the USA market, few studies reveal herding behavior. These few include a study of the German market by Naujoks et al. (2009) and of the Chinese market by Tsai-Hui et al. (2013).

Given this background, our first testing hypothesis is as follows:

H1: Analysts in the UK market herd. They herd regardless of whether they are issuing positive or negative forecasts.

According to Baker and Wurgler (2007), investor sentiment is a basic component of behavioral finance. Investor sentiment can be broadly defined as the mood and expectation about future cash flows or investment risks that are not justified by the facts at hand. In theory, those "irrational" investors who usually have less knowledge, trading experience and information processing skills, may be highly influenced by their sentiment and are more emotional than those who are traditionally considered rational investors or arbitrageurs. Under a general perspective, the influence of sentiment and irrational investors should be diversified away in a portfolio. But this is not necessarily the case in the presence of limited arbitrage and/or if unsophisticated investors do not trade randomly and follow positive-feedback strategies (they buy when prices rise and sell when prices fall).

According to De Long et al. (1990), many forms of behavior commonly found in financial markets may be described as positive feedback trading. As a general approach, positive feedback strategies can refer to a pattern of behavior in which a positive outcome gives the confidence to pursue further positive outcomes. This comes from emotional extrapolative expectations about prices or emotional trend chasing. But according to Smith et al. (1988), Scharfstein and Stein (1990), Lakonishok et al. (1991), Greenwood and Nagel (2009) or Bank and Brustbauer (2014), institutional, rational, sophisticated, and professional investors may be prone to sentiment too. In fact, the key to success for an investor is not only the ability to calculate an asset's fundamental value, but also to forecast actions, such 
as positive feedback strategies, of other investors. Therefore, even informed investors should track those features such as trading volume, price indicators and trend indicators that may reveal shifts in sentiment.

Evidence can be found in the financial literature of a significant relationship between investor sentiment and market returns (Baker and Wurgler (2006), Baker and Wurgler (2007), Brown and Cliff (2005) or Lee et al. (2002), among others). Additionally, the financial literature has shown that investor sentiment is a key variable for explaining analysts' behavior. It has been seen that in times of euphoria, analysts' forecasts tend to be more optimistic (Bagnoli et al. (2009)). A number of papers have shown analysts' inability to disassociate themselves from market optimism, which affects forecasting and recommendation processes separately (Qian (2009), Bagnoli et al. (2009), Hribar and McInnish (2012) or Corredor et al. (2013, 2014)). Along the same lines, Eickhoff and Muntermann (2016) relate analysts' reports with social media sentiment.

However, the translation of this effect to herding behavior is not obvious and has not yet been studied in depth. Why should analysts tend to herd differently when there is a positive or a negative feeling in the market? Because sentiment is perceived as being closely related with the consensus. Sentiment measures the emotional state of the capital market and indicates how bullish or bearish investors are in the market. It may therefore also influence many analysts' perceptions and opinions. In general, evidence from the field of psychology shows that people with positive sentiment tend to make optimistic choices and people with negative sentiment make pessimistic choices (Arkes et al. (1988), Bower (1981) and Wright and Bower (1992)). If, under specific circumstances, analysts tend to adjust their forecasts towards the consensus and avoid standing out from their peers, we should expect market sentiment to influence herd behavior.

Let us take the case of an analyst who receives negative information about the firm that he is analyzing. He is prone to make a negative recommendation or forecast. Should he be influenced by a largely positive market sentiment? Individuals have limited processing ability and they concentrate their time and attention on highly visible information. It is here where sentiment analysis comes into play. In a highly positive sentiment context, stock demand increases, prices rise and those following positive feedback strategies contribute to the positive feeling. As rational and professional agents, analysts may anticipate the reaction and may prefer to be cautious. They may tend to smooth their forecasts or 
recommendations, in order not to risk their prestige and remuneration, assuming that their peers do the same. The financial literature reports that analysts tend to underreact to negative information (and overreact to positive information) in order to improve access to management and, consequently, the accuracy of future forecasts (see, Das et al. (1998)). They need to cultivate a reputation for forecasting expertise, especially on the buy-side, if they want to achieve a higher professional status (Hong and Kubik (2003)). This scenario illustrates how investor sentiment can influence herding behavior by analysts when they need to combine a negative recommendation or forecast with positive investor sentiment (Simon and Curtis (2011) or Ke and Yu (2009) discuss the effectiveness of the translation of forecasts into recommendations). However, investor sentiment may cause an asymmetric reaction on the analyst's herding behavior when sentiment moves in the same direction as the recommendation or forecast. That is to say, when the forecast conveys positive expectations and the investor sentiment is high (or even when the forecast conveys negative expectations and the investor sentiment is low), the analyst could feel less constrained and less afraid to deviate from the consensus.

Therefore, the hypothesis to be tested may be formulated as follows:

\section{H2: Herding by analysts is influenced by investor sentiment but such an influence does not necessarily induce symmetric effects whether they release positive or negative information.}

Not all the recommendations or forecasts issued by analysts are made with the same level of difficulty, as Olsen (1996) states.

Difficult situations have been defined in the literature. Generally, they include situations when analysts issue negative forecasts or recommendations and, particularly, when negative forecasts or recommendations coincide with highly positive investor sentiment and when analysts are faced with hard-to- value stocks. Like any other market participant, analysts, although more informed, are also affected by limited attention which can have an impact on their forecasting ability and on their career outcomes (Choi and Gupta-Mukherjee (2016)). Limited attention and its consequences are more likely to appear when analysts evaluate hard-to-value stocks. In line with previous studies (Baker and Wurgler (2006)) among others), the assessment difficulty we want to analyze is most likely to be offered by small firms with high volatility, low dividends and high book-to-market values. 
According to these arguments, we propose our third hypothesis:

\section{H3: Herding by analysts is more likely to arise in difficult situations: H3a-when their information induces negative forecasts at times of highly positive investor sentiment}

H3b-when they have to forecast the future development of hard-to-value assets.

\section{3.-Data base}

Our analysis covers all non-financial firms listed on the London Stock Exchange from 1994 to 2016. According to the World Stock Exchange Federation, the London SE Group is Europe's largest in capitalization terms. This fact is an interesting feature for our research, because as far as we know the study of herding among analysts has been focused on the US market. Undoubtedly both the US and the UK markets share many similarities because both belong to the Anglo-Saxon system (low ownership concentration, high stock liquidity, and high level of creditor protection), and their private investors are characterized by an individualistic behaviour which could suggest a stronger propensity for herding practices. However, there are also some differences between these two markets such as their size and, particularly interesting in this case, the degree of analyst coverage. This is much lower in the UK market, which makes this market worth studying.

In order to obtain the variables required for calculating the herding measure, we use individual-level information provided by analysts' releases. Our analysis uses individual-level one-year-ahead (FY1) forecasts, consensus median EPS forecasts and actual earnings obtained by the firms in one fiscal year. In order to ensure data quality, any forecasts issued less than 90 days prior to firms' profits announcements were removed from the sample. This data is taken from the Factset database ${ }^{1}$. The reason for this choice of database is that it provides fuller coverage in Europe than the I/B/E/S (Balboa, et al. (2008)).

In line with Mensah and Yang (2008), this analysis includes control variables in order to rule out certain effects. One is the forecast horizon, which is taken as the number of days between an analyst's forecast issue and the end of that fiscal year (HOR). Another is the number of forecasts used (NEPS). The number of analysts

\footnotetext{
1 As well as the major international firms that regularly send their recommendations to $\mathrm{I} / \mathrm{B} / \mathrm{E} / \mathrm{S}$, contributors to this database include some domestic analysts, which results in wider coverage in European countries. Nevertheless, like other forecast databases, FactSet is affected by potential survivorship bias, and also selection bias, because it collects recommendations and forecasts from brokerage houses that collaborate on a voluntary basis. Correction of these two biases is not possible.
} 
following a firm in a given fiscal year is captured in the NAFF variable. Finally, changes in historical earnings stability (CHES) and average analyst forecasting errors (FERR) for a given firm in a given fiscal year are included in the model.

In order to observe the impact of analysts herding on different stocks, we group them into quintiles by size (SIZE), volatility (VOL), book-to-market ratio (BTM) and dividend per share (DPS) ${ }^{2}$. The group of stocks associated with the hardest to value, thus the most vulnerable to investor sentiment biases and herding effects, contains stocks characterized by extreme BTM ratios, low market cap value, high volatility and low dividend payouts. The data were sourced from Datastream (Thomson Financial).

The fact that the firms are sorted into quintiles for each stock characteristic allows a comparison between the extreme quintiles (the fifth and the first). Following papers dealing with the sensitivity of cognitive biases (Baker and Wurgler (2006) or Corredor et al. (2014) among others), the quintiles classed as hard-to-value (HVQ) include low market cap value stocks, low dividend payouts, high volatility stocks and high BTM ratios. The easy-to-value quintiles (EVQ) are the high market cap value stocks, high dividend payouts, low volatile stocks and high growth opportunities stocks.

There is a variety of investor sentiment measures although there is no consensus about which is the best proxy for this unobservable variable ${ }^{3}$. Some recent papers (Baker et al. (2012) and Chang et al. (2012)) build composite indicators that capture the commonality between various individual proxies and, more specifically, construct global sentiment indices from local sentiment indices.

Following this approach, in this paper two different sentiment indicators are used: the UK sentiment index as a proxy for a local sentiment index (SentUK) and a global sentiment index (SentGlobal) as a proxy for a world sentiment index, given that our sample of analysts and their brokerage houses all operate in a global setting.

Using principal component analysis (PCA), SentUK is obtained by means of 3 individual sentiment indicators: turnover, the volatility premium and the consumer confidence index ${ }^{4}$.

\footnotetext{
${ }^{2}$ Size is measured as the market capitalization and volatility is obtained as the standard deviation of stock returns for the previous twelve months

3 Previous studies include investor survey findings (Brown and Cliff (2005)), dividend premium (Baker and Wurgler (2004)), and turnover (Scheinkman and Xiong (2003)), among others.

4 The reason for the choice of these measures is their relationship with the level of sentiment used by Baker and Wurgler (2006), together with data availability. Constructional details of the turnover
} 
The same PCA procedure is used to construct the global investor sentiment index that captures the common component in the US sentiment and European (EU) sentiment. As a proxy for the US sentiment, we use the composite index constructed by Baker and Wurgler (2006, 2007), BW, which includes 6 different individual sentiment measures. The EU sentiment indicator is calculated as an index constructed using the commonality of the 4 local indexes corresponding to the four key European markets in cap terms, France, Germany, Spain and the UK. These domestic indexes, as in the case of SentUK, are calculated including consumer confidence, turnover and volatility premium.

Note that each sentiment index is likely to include a sentiment component as well as a common economic cycle component. For this reason, all individual measures are first orthogonalized by a series of macro-economic variables ${ }^{5}$ to explicitly remove the effect of possible changes in the economic cycle.

Our final database consists of 25648 observations involving 228 stocks and 3170 analysts belonging to 376 brokerage houses. Some descriptive statistics of the variables used are shown in Table 1.

\section{4.-Methodology and Results}

\section{1.-Measuring herding: the BCK-S statistic and results for hypothesis $H 1$}

Bernhardt et al (2006) propose a statistic for measuring herding or anti-herding in analyst forecasts. The BCK-S statistic is based on the probability that an analyst's unbiased forecast exceeds or falls short of the prior consensus by 0.5 , and is calculated by means of the following equation:

$$
S\left(z^{+}, z^{-}\right)=\frac{1}{2}\left[\frac{\sum_{\tau} \delta_{\tau}^{+}}{\sum_{\tau} \gamma_{\tau}^{+}}+\frac{\sum_{\tau} \delta_{\tau}^{-}}{\sum_{\tau} \gamma_{\tau}^{-}}\right]
$$

where $z_{\tau}^{+}$and $z_{\tau}^{-}$are conditioning events, $z_{\tau}^{+}$being when the analyst's forecast exceeds the extant consensus ${ }^{6}, z_{\tau}^{-}$being when it falls short and $\tau$ being the time

index can be found in Baker and Stein (2004), and those of the volatility premium in Baker et al. (2012). The consumer confidence index, which is available from the European Commission website, has been used in numerous studies, such as Brown and Cliff (2005), Lemmon and Portniaguina (2006), and Schmeling (2009), among others.

5 Following Baker and Wurgler (2006), and Schmeling (2009), the macroeconomic variables considered are the industrial output index, durable and non-durable goods consumption, and the unemployment rate.

${ }^{6}$ In order to reduce the EPS skewness effect, we consider the median consensus instead of the mean consensus. 
(quarterly/monthly intervals) to collect the forecasts. The conditioning indicator functions can be defined as follows:

$\gamma_{\tau}^{-}$is unity in the event of $z_{\tau}^{-}$and 0 otherwise.

$\gamma_{\tau}^{+}$is unity in the event of $z_{\tau}^{+}$and 0 otherwise.

The overshooting indicator functions are defined as follows:

$\delta_{\tau}^{-}$is unity in the event of $z_{\tau}^{-}$and the forecast falls short of the actual earnings and zero otherwise.

$\delta_{\tau}^{+}$is unity in the event of $z_{\tau}^{+}$and the forecast exceeds the actual earnings and zero otherwise.

$\mathrm{S}$ is the average of the two conditional probability estimates $\left[\frac{\sum_{\tau} \delta_{\tau}^{+}}{\sum_{\tau} \gamma_{\tau}^{+}}\right]$and $\left[\frac{\Sigma_{\tau} \delta_{\tau}^{-}}{\sum_{\tau} \gamma_{\tau}^{-}}\right]$, where $\left[\frac{\sum_{\tau} \delta_{\tau}^{+}}{\sum_{\tau} \gamma_{\tau}^{+}}\right]$is the estimate of the conditional probability of overshooting actual earnings given that the forecast exceeds the consensus and $\left[\frac{\sum_{\tau} \delta_{\tau}^{-}}{\Sigma_{\tau} \gamma_{\tau}^{-}}\right]$is the estimate of the conditional probability of falling short of true earnings given that the forecast falls short of the consensus. The null hypothesis that analysts' forecasts are unbiased implies that $\mathrm{S}$ is 0.5 . $\mathrm{S}<0.5$ would indicate the presence of herding by analysts, while $\mathrm{S}>0.5$ would indicate anti-herding. It is interesting to note that each component of the $\mathrm{S}$ statistic is valuable, given that it computes the conditional probability of overshooting or underestimating actual earnings.

The literature has provided measures for testing for herding by analysts: Olsen (1996) (where it is measured as the relative tightness of forecast distribution); De Bondt and Forbes (1999) (which uses the cross-sectional dispersion of forecasting accuracy); Chen and Jiang (2006) (underweighting of private information); Clement and Tse (2005) (comparison of forecast with deviation from consensus and previous forecast), among others. The BCK-S statistic appears superior to previous measures (Olsen (1996); De Bondt and Forbes (1999); Chen and Jiang (2006) or Clement and Tse (2005) among others) because it is conservative in the presence of cross-sectional correlation and robust to forecast target mismeasurement and systematic optimism by analysts, both of which could lead only to Type II errors. Being non-parametric, moreover, this test is unaffected by the magnitude of the errors.

Table 2 shows the quarterly and monthly estimates of the BCK-S statistic for all stocks without being differentiated by the difficulty of their assessment. This analysis considers all forecasts, with or without the analysts' name, and also 
taking into account the Hribar and McInnis (2012) procedure of removing stocks with less than 0.10 pounds forecasts.

Because $\mathrm{S}$ is strictly lower than 0.5 in both time frequencies, the results suggest the presence of herding, especially using monthly information which is expected to be more accurate. The persistence of the estimates for both also suggests the robustness of the calculations, showing clear evidence that analysts herd in the UK market and, therefore, that hypothesis 1 is confirmed. However, it should be emphasized that mimetic behavior is more intense when analysts give pessimistic information.

4.2.-Measuring the effect of investor sentiment on herding and the results of hypothesis $\mathrm{H} 2$.

Since it has become clear that analysts herd around the consensus, Hypothesis 2 examines whether investor sentiment influences the analysts' herding behavior. To address this question, the following model is estimated:

$S_{i, t}=\beta_{0}+\beta_{1} \operatorname{Sent}+\beta_{2} N E P S+\beta_{3} H O R+\beta_{4} N A F F+\beta_{5} C H E S+\beta_{6} F E R R+u_{i, t}$

where $\mathrm{S}_{\mathrm{i}, \mathrm{t}}$ is the dependent variable which captures the value of the measure used as a proxy for herding behavior (BCK-S statistic) with respect to firm i during the month $t ; B_{p}$ denotes the coefficient estimates and $u_{i t}$ is the error term. Sent denotes the investor sentiment variable. Since we want to test whether the effect of investor sentiment has a local or more global connotation, we estimate three different dimensions of investor sentiment. We differentiate between the local sentiment calculated using UK data and the global sentiment calculated using international/worldwide data and, finally, a joint effect.

Additionally, in line with Mensah and Yang (2008), we include the control variables ${ }^{7}$ described in the previous section. In the OLS estimation, the standard errors are clustered by stock and adjusted for heteroskedasticity and serial autocorrelation. Year dummies are also included to check for time effects.

In order to observe the effect of investor sentiment on the two components of the BCK-S statistic, two additional estimations of Equation 2 are carried out considering as dependent variables either the probability of a positive forecast (above current earnings given that the forecast exceeds the extant consensus) or

7 The observations are winsorized at the $99 \%$ level. 
the probability of a negative forecast (below current earnings given that the forecast falls short of the extant consensus).

The results are presented in Table $3^{8}$. Panel A shows the estimates when local sentiment is used. It can be confirmed that investor sentiment has a significant effect on analysts' herding behavior. In fact, the BCK-S statistic indicates that the greater the optimism, the lower the $\mathrm{S}$ value, implying more herding. The effect on both components of $\mathrm{S}$ is also significant. However, it is noted that in optimistic situations when investor sentiment is high, analysts transmitting positive views tend to imitate each other less whereas they tend to imitate more intensively when transmitting negative views.

These results show that local sentiment in the UK affects the behavior of analysts reporting in this market. However, some papers such as Chang et al. (2012), Baker et al. (2012) or Corredor et al. (2013), among others, find that the effect of investor sentiment is a global phenomenon. Panel B presents the corresponding estimates for equation 2 when the global sentiment is considered. The results are also significant at the $1 \%$ significance level in the case of positive forecasts, given that an increase in investor sentiment induces an increase in the herding measure, indicating a lower herding level. In the case of negative opinions, the influence of market sentiment on the herding measure is also significant but negative at the $1 \%$ significance level. Globally considered, it could be said that the effect of global sentiment on each component of the BCK-S statistic is consistent with the results obtained using the local sentiment. The results using the local and the global sentiment individually, although with different significance levels, indicate that investor sentiment influences analysts' herding behavior. Given these results, it may be of interest to know the interaction between these two sentiment measures, given that both sentiment indices may share some common information. A causality analysis was therefore carried out to determine their relationship ${ }^{9}$. The results of the Granger test did not allow us to reject the null hypothesis that one sentiment measure causes the other. Nevertheless, in order to correct the possible influence of the global sentiment on the local sentiment, the local sentiment was

\footnotetext{
${ }^{8}$ For the sake of clarity, in the remainder of the paper we report only the estimations performed on named analysts' forecast data using the method employed in Hribar and McInnis (2012). It is worth noting, however, that the results coincide with those obtained using the alternative sample.

9 The causality test was carried out through a VAR technique where both indices were included. According to the ADF test, all the variables are stationary. The criterion for the lag choice was the Schwarz criterion.
} 
orthogonalized so that it could be divided into two parts, the global sentiment component and the specific UK component free of global effects.

The model proposed to test the joint influence of the global component and the strictly local component of sentiment is as follows:

$S_{i, t}=\beta_{0}+\beta_{1}$ Sent $+\beta_{2}$ ResSentOrtogonal $+\beta_{3} N E P S+\beta_{4} H O R+\beta_{5} N A F F+\beta_{6} C H E S+$

$\beta_{7} F E R R+u_{i, t}$

where the variables included are defined as in eq. (2), Sent is the global component and ResSentOrtogonal is the local sentiment free of the global influence.

The results for these estimates are shown in table 3 Panel C. As expected, these results confirm the relevance of investor sentiment, either under a local or a global perspective, and the asymmetric effect on the herding measure when analysts release more positive information and when they issue more negative forecasts.

We can conclude that analysts are influenced by investor sentiment differently depending on the type of recommendation being released. If there is optimism in the market and analysts have to issue more positive perspectives, they do not mind deviating from the consensus because they do not expect significant negative consequences if they make an individual mistake or overestimate their forecasts. However, when analysts issue more negative perspectives, they prefer to move closer to the consensus in order to avoid reputational costs.

\section{3- Investor Sentiment in difficult situations. The result of $H 3$.}

Analysts in the UK are influenced by investor sentiment. Depending on such sentiment and their own information and analysis, they tend to intensify their herding tendency or otherwise.

In order to explore the influence of sentiment in more difficult situations, hypothesis 3 is split into two parts. Hypothesis H3a refers to cases in which analysts' information induces negative forecasts at times of high sentiment. The results and the interpretation of this first difficult situation can once again be found in the last columns of table 3 . When analysts transmit negative forecasts and investor sentiment is optimistic, they feel less confident and tend to herd more intensively.

The purpose of H3b is to test whether analysts' herd behavior becomes more intensive when they have to forecast the future development of hard-to-value 
assets. Initially this hypothesis could be tested only taking into account the type of asset as an explanatory variable of the herding measure. However, the literature relating to the influence of sentiment on asset returns has also shown that this effect is enlarged when forecasting the most hard-to-value assets. Perhaps the results concerning sentiment and hard-to-value stocks may be combined or could complement each other. If analysts herd more when they analyze hard-to-value stocks at specific moments when optimistic investor sentiment plays an important role and, additionally, investor sentiment particularly affects hard-to-value assets, it is possible that the effect of hard-to-value assets on herding may be due to sentiment. Three models have been used to test hypothesis H3b. The first model (eq. 4) simply tries to test the influence of the type of asset on the herding measure. As already mentioned, the firms in the sample have been ranked according to four variables: volatility, size, book-to-market ratio and dividend payout. The portfolios including those companies with lowest volatility, largest size, lowest BTM and that pay the highest dividends are considered easy-to-value (EVQ) firms whereas hardto-value (HVQ) companies are those included in the quintile with the highest volatility, smallest size, largest BTM and those that do not pay dividends.

$S_{i, t}=\beta_{0}+\beta_{1} E V Q+\beta_{2} H V Q+\beta_{3} N E P S+\beta_{4} H O R+\beta_{5} N A F F+\beta_{6} C H E S+\beta_{7} F E R R+u_{i, t}$

The second model (eq. 5) includes as independent variables both sentiment and the extreme quintile portfolios calculated for all the characteristics under study.

$S_{i, t}=\beta_{0}+\beta_{1} \operatorname{Sent}+\beta_{2} E V Q+\beta_{3} H V Q+\beta_{4} N E P S+\beta_{5} H O R+\beta_{6} N A F F+\beta_{7} C H E S+$ $\beta_{8} F E R R+u_{i, t}$

In these equations (4 and 5) the variables, NEPS, HOR, NAFF, CHES and FERR are defined as in eq.3, the variable associated with investor sentiment is taken as local sentiment given its significance in our previous results, and two additional variables are included representing extreme quintiles: EVQ, a dummy variable that takes value 1 when the firm is in the "easy-to-value" quintile and 0 otherwise; HVQ, a dummy variable that takes value 1 if the stock is considered as a "hard-to-value" asset and 0 otherwise. The equations are estimated 4 times taking volatility, size, book-to-market and dividends as variables that identify the difficulty of valuation. 
When analysts face hard-to-value stocks, sentiment may also have an asymmetric effect. When there is high investor sentiment in the market, analysts may feel more confident following the consensus when they evaluate hard-to-value stocks whereas such an effect is not as clear when they face easy-to-value stocks. Corredor et al. (2016) find that the effectiveness of analysts' recommendations is reduced by investor sentiment only in relation to highly sentiment-sensitive stocks. It is therefore of interest to test whether sentiment may enhance analysts' herding when they deal with hard-to-value stocks.

So, equation (6) also includes the interaction effect between investor sentiment and the extreme quintiles, in order to test the possible relation between sentiment and the asset characteristics.

$S_{i, t}=\beta_{0}+\beta_{1} \operatorname{Sent}+\beta_{2} E V Q+\beta_{3} H V Q+\beta_{4} \operatorname{SentEVQ}+\beta_{5} \operatorname{SentHVQ}+\beta_{6} N E P S+\beta_{7} H O R+$ $\beta_{8} N A F F+\beta_{9} C H E S+\beta_{10} F E R R+u_{i, t}$

The corresponding estimates are found in Tables $4^{10}$ and 5 . When only the extreme quintiles are considered, the results for the S statistic (table 4) indicate that analysts ${ }^{\prime}$ herding significantly decreases in the case of easy-to-value stocks ${ }^{11}$. The results for the components of the $\mathrm{S}$ statistic also reveal that when the dependent variable is the probability of more positive forecasts (above current earnings) we do not find significant results, indicating that analysts do not modify their herding behavior (except in the case of the largest/smallest size stocks, where analysts decrease/increase their mimetic tendency). Nevertheless, when analysts release more negative recommendations or forecasts, they tend to herd less when they are evaluating easy-to-value stocks ${ }^{12}$.

When investor sentiment is included in the analysis (table 5), this behavioral pattern is maintained and sentiment has a negative effect on $\mathrm{S}$, i.e. increasing herding activity. When the interaction between investor sentiment and the type of assets is included, the corresponding estimate does not offer significant results at a $5 \%$ significance level, and we cannot conclude that analysts tend to herd more

\footnotetext{
${ }^{10}$ Henceforth, for the sake of clarity, we present only the monthly estimates. The quarterly estimates, which are consistent with the latter, are available from the authors upon request.

${ }^{11}$ When the size variable is used to classify the assets, it is also observed that herding increases in hard-to-value portfolios.

${ }^{12}$ When the volatility variable is used to classify the assets, it is also observed that herding increases in hard-to-value portfolios.
} 
intensively when analyzing sentiment-sensitive stocks at times of high investor sentiment ${ }^{13}$.

The results for the components of the $\mathrm{S}$ statistic also reveal robustness when analysts issue forecasts below current earnings: sentiment increases herding whereas easy-to-value stocks lead to reduced herding. Therefore, when there is high optimistic sentiment in the market and analysts' views are negative, these analysts are prone to herd in order to avoid negative consequences for their prestige and remuneration should their negative forecasts prove to be incorrect. This is not the case when they are assessing easy-to-value stocks, given that in this case analysts feel more confident in their views and reduce their herding behavior. The results of the estimates when the dependent variable is the probability of positive forecasts (i.e. above current earnings) are different and coincide with the results obtained when $\mathrm{H} 2$ was tested: when analysts transmit positive forecasts and investor sentiment is optimistic, they feel more confident and tend to follow their own beliefs. We do not find significant results in the herding of analysts when they forecast hard or easy assets, indicating that they do not modify their herding behavior (except in the case of the largest size stocks, where analysts decrease their mimetic tendency and in the smallest size stocks where the herding increases).

When the interaction component is included in the model, the significance of investor sentiment and the significance of the results obtained for easy-to-value stocks remain robust.

We can conclude that the estimates of the $\mathrm{S}$ statistic could suggest that, generally speaking, sentiment increases herding whereas easy-to-value stocks reduce it. However, it is worth mentioning that such a general conclusion does not hold if the $\mathrm{S}$ statistic is split into its two components, that is, it does not hold for every type of analysts' recommendation. Investor sentiment affects analysts' herding behavior differently depending on the analysts' views. However, it seems clear that analysts tend to reduce their imitative behavior when they forecast easyto-value stocks, regardless of investor sentiment at the time.

\section{5.-Conclusions}

\footnotetext{
13 The influence on the $\mathrm{S}$ statistic is only significant for hard-to-value portfolios when the assets are ranked by size, for which mimetic behavior intensifies when sentiment and portfolio are taken into account.
} 
The aim of this paper is to test whether investor sentiment may influence herding practices among analysts in the UK market. For this purpose, we use the BCK-S statistic (Bernhardt et al. (2006)) which is based on the conditional probability that an analyst's unbiased forecast exceeds or falls short of the prior consensus. Besides its global usefulness, this statistic enables us to analyze herding practices both in the case of optimistic releases and pessimistic releases. In particular, we want to test whether two specific difficult situations may increase herding levels among analysts; the case in which analysts' information leads to negative forecasts at times of high sentiment and the case in which they have to forecast the future development of hard-to-value assets and such a difficulty may interact with sentiment.

Our main results indicate that sentiment clearly affects herding among analysts. However, this influence is not symmetric if analysts release optimistic or pessimistic information. Herding decreases when analysts release optimistic information at times when market sentiment is positive. In contrast, herding tends to increase when analysts release pessimistic information when investor sentiment is high. We conjecture that this latter situation is explained by analysts attempting to avoid negative consequences for their prestige and remuneration if their own individual negative forecasts or recommendations prove to be mistaken, given that collective errors are usually penalized less than individual errors.

However, the herding increase induced by the "difficult" situation of releasing a pessimistic forecast which goes against the market sentiment, as well as the herding decrease induced by the "easy" situation of releasing a positive forecast at times of high sentiment, may vary depending on the degree of difficulty that analysts find when they analyze a specific firm. Easy-to-value companies represent an easier situation for analysts than hard-to-value companies. Our results indicate that easy-to-value stocks tend to decrease herding behavior among security analysts, particularly when they release pessimistic information. But the interaction between easy-to-value stocks and market sentiment is not significant and does not modify the existing herding behavior.

However, in general hard-to-value stocks do not significantly increase herding among analysts, and neither does the interaction between hard-to-value stocks and sentiment. When analysts face hard-to-value stocks, they may employ internal mechanisms that assess contextual factors and determine that the profits to be made from following their peers are not sufficient to outweigh the possible cost of 
an individual error, perhaps because there is no clear consensus to follow given the degree of difficulty. Herding in this "difficult" situation may only marginally increase their payoff due to the insufficient reward provided as compared to the psychological cost of not following their beliefs. This reasoning could raise the question: how do analysts determine when herding is appropriate?

To sum up, the results of this paper suggest that, on the one hand, "easy situations" such as analyzing easy-to-value securities and releasing optimistic information at times of high market sentiment clearly reduce herding practices, whereas herding clearly increases when analysts release more negative information at moments of high sentiment. It is to be expected that this last result is scarcely avoidable, despite the existence of regulations designed to ensure impartial investment recommendations and the avoidance of conflicts of interest that could undermine disclosure. The reaction to market sentiment and the tendency to herd, even when rationally justified by a conscious decision not to risk the analyst's prestige or remuneration, cannot be easily identified and consequently controlled. In this case, institutional investors or other sophisticated investors can try to make a profit from this bias if they can detect that such a herding reaction is taking place. Nevertheless, if this effect of sentiment on herding practices is anticipated and discounted when investors take their investment decisions, the final effect on the market should not be significant.

The framework of this paper is limited to a single country and, therefore, the conclusions obtained are valid for the same or, at most, a similar environment. The possible extension of the area of study to other countries with differentiated characteristics would enrich its scope and allow the conclusions to be generalized. In addition, this analysis includes a time period in which the Brexit has not yet materialized, so future expansion of the work would have the advantage of knowing the implications of this or other similar significant events on the behavior of analysts. Future research could be oriented to the analysis of event studies in general and their effects on the herding of analysts. Following this approach, broadening the database of analysts by including other countries together with a consideration of events or circumstances that may imply structural changes might be of interest from the point of view of deepening our knowledge and understanding of analysts' behavior ${ }^{14}$.

\footnotetext{
${ }^{14}$ We appreciate this idea suggested by the anonymous reviewers
} 


\section{REFERENCES}

Arkes, H; Herren, L; Isen A. 1988. "The role of potential loss in the influence of affect on risk taking behavior" Organizational Behavior and Human Decision Processes, 35, 124-140.

Baker, M.; Stein, J. 2004. "Market Liquidity as a Sentiment Indicator", Journal of Financial Markets, 7, 271-299.

Baker, M.; Wurgler, J. 2004. "Appearing and Disappearing Dividends: the Link to Catering Incentives" Journal of Financial Economics, 73, 271-288.

Baker, M; Wurgler, J. 2006. "Investor sentiment and the cross-section of stock returns" The Journal of Finance, 61, 4, 1645-1680.

Baker, M; Wurgler, J. 2007. "Investor Sentiment in the Stock Market" Journal of Economic Perspectives, 21, 129-151.

Baker, M; Wurgler, J.; Yu, Y. 2012 "Global, Local, and Contagious Investor Sentiment" Journal of Financial Economics, 104, 272-287.

Bagnoli, M; Clement, M; Crawley, M; Watts, S. 2009. "The profitability of analysts' stock recommendations: What role does investor sentiment play?" Working Paper. (July 3, 2009). Available at SSRN: http://ssrn.com/abstract=1430617.

Balboa, M; Gómez-Sala, J.C; Lopez-Espinosa, G. (2008) "Does the value of recommendations depend on the level of optimism? A country-based analysis" Journal of Multinational Financial Management, 18, 405-426.

Bank, M; Brustbauer, J. 2014. "Investor sentiment in financial markets" Working paper, University of Innsbruck. January, 21.

Bernhardt, D; Campello, M; Kutsoati, E. 2006. "Who herds?" Journal of Financial Economics, 80, 657-675.

Bikhchandani, S; Sharma, S. 2000. "Herd Behavior in Financial Markets: A Review" IMF Staff Papers, 47(3), 279-310.

Bower, G. 1981. "Mood and memory" American Psychologist, 36, 129-148.

Brennan, M. J; Li, F. 2008. "Agency and Asset Pricing” (March 11, 2008). Available at SSRN: $\underline{\text { http://ssrn.com/abstract }=1104546}$

Brown, G.W; Cliff, M.T. 2005. "Investor Sentiment and Asset Valuation" Journal of Business, 78, 405-440.

Chang, C; Faff, R.W; Hwang, C.-Y. 2012. "Local and Global Sentiment Effects, and the Role of Legal, Information and Trading Environments". (February 28, 2012). Available at SSRN: http://ssrn.com/abstract $=1800550$

Chen, Q; Jiang, W. 2006. "Analysts Weighting of Private and Public Information" Review of Financial Studies, 19(1), 319-355.

Choi, H. M.; Gupta-Mukherjee, S. 2016. "Does Limited Attention Matter in Security Analysis? Evidence from Analysts' Reliance on Categories" (August 25, 2016). Available at SSRN: http://ssrn.com/abstract=2692406

Clement, M.B; Tse, S.Y. 2005. "Financial analyst characteristics and herding behavior in forecasting" Journal of Finance, 60, 1, 307-341.

Corredor, P; Ferrer, E; Santamaría, R. 2013. "Value of Analysts' Consensus Recommendations and Investor Sentiment", Journal of Behavioral Finance, $14: 3,213-229$ 
Corredor, P; Ferrer, E.; Santamaría, R. 2014. "Is cognitive bias really present in analysts'forecasts? The role of investor sentiment" International Business Review, 23, 824-837.

Corredor, P; Ferrer, E; Santamaría, R. 2016. "The role of sentiment and stock characteristics in the translation of analysts'forecasts into recommendations" IFABS Conference, Barcelona, Spain.

Das, S; Levine, C. B; Sivaramakrishnan, K. 1998. "Earnings predictability and bias in analysts' earnings forecasts" Accounting Review, 277-294.

De Bondt, W.F.M; Forbes, W.P. 1999. "Herding in analyst earnings forecasts: evidence from the United Kingdom" European Financial Management, 5, 2, 143163.

De Long, J.B; Shleifer, A; Summers, L.H; Waldmann, R.J. 1990. Positive feedback investment strategies and destabilizing rational speculation. The Journal of Finance, XLV, 2, 379-395.

Easterwood, J.C; Nutt, S.R. 1999. "Inefficiency in Analysts Earnings Forecasts: Systematic Misreaction or Systematic Optimism?” Journal of Finance, 54(5), 1777-1797.

Eickhoff, M; Muntermann, J. 2016. "Stock analysts vs. the crowd: Mutual prediction and the drivers of crowd wisdom" Information and Management, 53, 835-845.

Elster, J. 1998. "Emotions and economic theory" Journal of Economic Literature, 36, 47-74.

Francis, J; Philbrick, D. 1993. "Analysts' decisions as products of a multi-task environment" Journal of Accounting Research, 31, 216-230.

Francis, J; Soffer, L. 1997. "The relative informativeness of analysts' stock recommendations and earnings forecast revisions" Journal of Accounting Research, 35, 193-211.

Fredericksons, J.R; Miller, J.S. 2004. "The Effects of Pro Forma Earnings Disclosures on Analysts' and Nonprofessional Investors' Equity Valuation Judgments" The Accounting Review, 79, 3, 667-686.

Givoly, D; Lakonishok, J. 1984. "Properties of analysts' forecasts of earnings: A review and analysis of the research" Journal of Accounting Literature, 3, (spring), 117-152.

Greenwood, R; Nagel, S. 2009. "Inexperienced investors and bubbles" Journal of Financial Economics 93(2), 239-258.

Hirshleifer, D; Teoh, S.H. 2003. "Herd behavior and cascading in capital markets: a review and synthesis" European Financial Management, 9, 1, 25-66.

Hong, H; Kubik, J. D. 2003. "Analyzing the Analysts: Career Concerns and Biased Earnings Forecasts" The Journal of Finance, 58, 313-351.

Hribar, P; McInnis, J. 2012. "Investor Sentiment and Analysts' Earnings Forecast Errors" Management Science, 293-307.

Jegadeesh, N; Kim, W. 2010. "Do analysts herd? An analysis of recommendations and market reactions" Review of Financial Studies, 23, 2, 901-937.

$\mathrm{Ke}, \mathrm{B}$; Yu, Y. 2009. "Why don't analysts use their earnings forecasts in generating stock recommendations?, Available at SSRN: http://ssrn.com/abstract=1011449 or http://dx.doi.org/10.2139/ssrn.1011449 
Kim, C; Pantzalis, C. 2003. "Global/Industrial Diversification and analyst herding" Financial Analysts Journal, 59, 2, 69-79.

Krishnan, M; Lim, S; Zhou, P. 2005. "Who herds? Who doesn't?" http://ssrn.com/abstract=850625.

Lakonishok, J; Shleifer, A; Thaler, R.H; Vishny, R.W. 1991. Window dressing by pension fund managers. American Economic Review Papers and Procedings, 81(2), 227- 231.

Lee, W.Y; Jiang, C.X; Indro, D.C. 2002. Stock market volatility, excess returns, and the role of investor sentiment. Journal of Banking and Finance 26(12), 22772299 .

Lemmon, M; Portniaguina, E. 2006. "Consumer Confidence and Asset Prices: Some Empirical Evidence" Review of Financial Studies, 19, 1499-1529.

Lin H-W; McNichols, M.F. 1998. "Underwriting relationships, analysts' earnings forecasts and investment recommendations" Journal of Accounting and Economics, 25, 101-127.

Loewenstein, G. 2000. "Emotions in economic theory and economic behavior" American Economic Review, 90, 426-432.

Lo, A. 1999. “The three P's of total risk management” Financial Analysts Journal, $55,12-20$.

Maug, E; Naik, N. 2011. "Herding and delegated portfolio management: The Impact of Relative Performance Evaluation on Asset Allocation" Quarterly Journal of Finance, 1, 265-292.

Mensah, Y.M; Yang, R. 2008. "An empirical evaluation of analysts' herding behavior following Regulation Fair Disclosure" Journal Accounting Public Policy, 27, 317-338.

Michaely, R; Womack, K.L. 1999. "Conflict of interest and the credibility of underwriter analyst recommendations" Review of Financial Studies, 12, 653686.

Naujoks, M; Aretz, K; Kerl, A. G; Walter, A. 2009. "Do German security analysts herd? Financial Market Portfolio Management, 23, 3-29.

Olsen, R.A. 1996. "Implications of herding behavior for earnings estimation, risk assessment, and stock returns" Financial Analysts Journal, 52, 4, 37-41.

Peters, E; Slovic, P. 2000. "The springs of action: Affective and analytical information processing in choice" Personality and Social Psychology Bulletin, 26, 1465-1475.

Qian, H. 2009. "Time Variation in Analyst Optimism: an Investor Sentiment Explanation", Journal of Behavioral Finance, 10, 182-193.

Rajan, R. G. 1994. "Why credit policies fluctuate: A theory and some evidence" Quarterly Journal of Economics, 436, 399-442.

Ramnath, S; Rock, S; Shane, P. 2008. "A Review of Research Related to Financial Analysts Forecasts and Stock Recommendations" International Journal of Forecasting, 24(1), 34-75.

Roll, R. 1992. "A mean/variance analysis of tracking error" Journal of Portfolio Management, summer, 13-22.

Scharfstein, D.S; Stein, J.C. 1990. "Herd behavior and investment" American Economic Review, 80, 465-479. 
Scheinkman, J; Xiong, W. 2003. "Overconfidence and Speculative Bubbles" Journal of Political Economy, 111, 1183-1219.

Schmeling, M. 2009 "Investor sentiment and stock returns: some international evidence" Journal of Empirical Finance, 16, 394-408.

Shefrin, H. 2000. "Beyond greed and fear; Understanding behavioral finance and the psychology of investing" Cambridge: HBS Press.

Simon, A; Curtis, A. 2011. "The use of earnings forecasts in stock recommendations: are accurate analysts more consistent?" Journal of Business, Finance \& Accounting, 38, 119-144.

Smith, V.L; Suchanek, G.L; Williams A.W. 1988. Bubbles, crashes, and endogenous expectations in experimental spot asset markets. Econometrica 56(5),1119-1151.

Thaler, R. 1991. "Quasi-rational economics", New York: Russel Sage Foundation.

Trueman, B. 1994. "Analyst Forecasts and herding behaviour" Review of Financial Studies, 7, 97-124.

Tsai-Hui, L.; Woan-Yuh, J; Seng-Su, T. 2013. "Do security analysts herd on stock recommendations and does it affect returns? International Journal of Economics and Finance, 5, 6, 67-83.

Wright, W.F; Bower, G.H. 1992. Mood effects on subjective probability assessment. Organizational Behaviour and Human Decision Processes, 52, 276-291.

Zitzewitz, E. 2001. "Measuring herding and exaggeration by equity analysts" Working paper. Stanford University, Graduate School of Business. 
Table 1. Sample descriptive statistics. This table presents the descriptive statistics for the sample. Volatility (VOL) is the last twelve months' standard deviation in percentage terms. Size (SIZE) is the stock market capitalization of each firm in millions of Euros. The book-to-market ratio (BTM) is the ratio between the two values. Dividend (DPS) is the end of month dividend per share ratio. Sent UK is the local investor sentiment. Sent Global is a proxy of the world sentiment index. FE is the mean of the forecast earnings error. It is calculated as the actual earnings minus the EPS forecast for the fiscal year and scaled by the absolute value of the EPS forecast. Forecast horizon (HOR) is the number of days between an analyst's forecast issue and the end of that fiscal year. Number of forecasts (NEPS). Number of analysts following a firm (NAFF) is the sum of all analysts following a given firm in a given fiscal year. Changes in historical earnings stability (CHES) is the standard deviation of the last five years' earnings. Average analyst forecasting errors for a given firm in a given fiscal year (FERR).

\begin{tabular}{rrrrrr} 
Variable & Mean & StDev & $1^{\text {st }}$ quartile & Median & $3^{\text {rd }}$ quartile \\
\cline { 1 - 5 } Firms & & & & & \\
VOL & 0.10 & 0.04 & 0.08 & 0.09 & 0.12 \\
SIZE & 4224.99 & 11429.47 & 268.47 & 818.67 & 2139.68 \\
BTM & 0.62 & 0.38 & 0.34 & 0.55 & 0.84 \\
DPS & 10.14 & 13.02 & 1.83 & 6.59 & 13.51 \\
\hline Sentiment & & & & & \\
Sent UK & 0.07 & 0.99 & -0.49 & -0.25 & 0.76 \\
Sent Global & -0.10 & 0.94 & -0.69 & 0.06 & 0.37 \\
\hline Analysts & & & & & \\
FE & -0.02 & 0.48 & -0.29 & -0.09 & 0.39 \\
NEPS & 7.81 & 6.32 & 3.00 & 6.00 & 10.00 \\
HOR & 186.84 & 102.78 & 96.00 & 185.00 & 281.00 \\
NAFF & 8.18 & 5.08 & 4.67 & 7.00 & 10.14 \\
CHES & 0.23 & 0.49 & 0.05 & 0.11 & 0.23 \\
FERR & 0.11 & 1.06 & -0.10 & -0.01 & 0.11 \\
\hline
\end{tabular}

Table 2. Results of the quarterly and monthly estimations of the $\mathrm{S}$ statistic for one-year forecasts FY1, over the firm sample as a whole. (a) Obtained using all available analyst forecast data and (b) obtained removing stocks with absolute earnings forecasts of less than 0.10 euros. Ninety-five percent confidence intervals are reported in square brackets. $\operatorname{Pr}(\mathrm{F}>\mathrm{A})$ indicates the probability of the analyst forecast exceeding actual earnings ( $\mathrm{F}$ value of the analyst forecast, A: realized earnings). $\operatorname{Pr}\left(\mathrm{F}>\mathrm{A} / \mathrm{z}^{+}\right.$) is the first component of $\mathrm{S}$ which indicates the probability of the analyst forecast exceeding actual earnings conditioned to $\mathrm{z}^{+}, \operatorname{Pr}(\mathrm{F}<\mathrm{A} / \mathrm{z})$ the second component of $\mathrm{S}$ which indicates the probability of the analyst's forecast being lower than actual earnings conditioned to $\mathrm{z}$.

\begin{tabular}{lccccc} 
& $\mathbf{N}$ & $\operatorname{Pr}(\mathbf{F}>\mathbf{A})$ & $\operatorname{Pr}(\mathbf{F}>\mathbf{A} / \mathbf{z}+)$ & $\operatorname{Pr}(\mathbf{F}<\mathbf{A} / \mathbf{z}-)$ & $\mathbf{S}$ \\
\hline (a)Quarterly Data & 12955 & 0.461 & 0.504 & 0.488 & 0.496 \\
& & & & & {$[0.491 ; 0.501]$} \\
(b)Quarterly Data & 12223 & 0.456 & 0.501 & 0.493 & 0.497 \\
& & & & & {$[0.492 ; 0.502]$} \\
(a)Monthly Data & 25648 & 0.481 & 0.497 & 0.471 & 0.484 \\
& & & & & $0.480 ; 0.488]$ \\
(b)Monthly Data & 24089 & 0.477 & 0.496 & 0.474 & 0.485 \\
& & & & & {$[0.481 ; 0.489]$} \\
\hline
\end{tabular}


Table 3. Results of regression analysis of the sentiment effect on herding. $\mathrm{S}_{\mathrm{i}, \mathrm{t}}$ is the dependent variable that captures the value of the proxy herding statistic for firm i during month (quarter) t. Sent is the proxy of investor sentiment. Local (panel A), global (panel B) sentiment measures and global and orthogonal local sentiments (panel C). HOR (average age of forecasts used to estimate S), NEPS (number of individual forecasts), NAFF (number of analysts following a firm), CHES (standard deviation of quarterly earnings per share), FERR (average forecast error for each firm-period).

\begin{tabular}{|c|c|c|c|c|c|c|c|c|c|c|c|c|}
\hline \multirow{3}{*}{$\begin{array}{c}\text { Panel A } \\
B_{\mathrm{s}}\end{array}$} & \multicolumn{6}{|c|}{ Quarterly Data } & \multicolumn{6}{|c|}{ Monthly Data } \\
\hline & \multicolumn{2}{|c|}{$\mathrm{S}$} & \multicolumn{2}{|c|}{$\operatorname{Pr}(\mathrm{F}>\mathrm{A} / \mathrm{z}+)$} & \multicolumn{2}{|c|}{$\operatorname{Pr}(\mathrm{F}<\mathrm{A} / \mathrm{z}-)$} & \multicolumn{2}{|c|}{$\mathrm{S}$} & \multicolumn{2}{|c|}{$\operatorname{Pr}\left(\mathrm{F}>\mathrm{A} / \mathrm{z}^{+}\right)$} & \multicolumn{2}{|c|}{$\operatorname{Pr}(\mathrm{F}<\mathrm{A} / \mathrm{z}-)$} \\
\hline & coef & $\begin{array}{c}\mathrm{p}- \\
\text { value }\end{array}$ & coef & $\begin{array}{c}\text { p- } \\
\text { value }\end{array}$ & coef & $\begin{array}{c}\mathrm{p}- \\
\text { value }\end{array}$ & coef & $\begin{array}{c}\mathrm{p}- \\
\text { value }\end{array}$ & coef & $\begin{array}{c}\mathrm{p}- \\
\text { value }\end{array}$ & coef & $\begin{array}{c}\mathrm{p}- \\
\text { value }\end{array}$ \\
\hline Sent & & & & & & & & & & & & \\
\hline local & -0.005 & 0.09 & 0.011 & 0.08 & -0.021 & 0.00 & -0.006 & 0.04 & 0.031 & 0.00 & -0.043 & 0.00 \\
\hline NEPS & 0.003 & 0.00 & 0.002 & 0.01 & 0.003 & 0.00 & 0.007 & 0.00 & 0.008 & 0.00 & 0.007 & 0.00 \\
\hline HOR & -0.001 & 0.00 & 0.000 & 0.46 & -0.001 & 0.00 & -0.001 & 0.00 & 0.000 & 0.53 & -0.001 & 0.00 \\
\hline NAFF & 0.007 & 0.00 & 0.010 & 0.00 & 0.002 & 0.18 & 0.006 & 0.00 & 0.009 & 0.00 & 0.002 & 0.23 \\
\hline CHES & 0.001 & 0.76 & 0.001 & 0.40 & -0.001 & 0.66 & 0.001 & 0.04 & 0.001 & 0.02 & 0.001 & 0.74 \\
\hline FERR & -0.007 & 0.28 & -0.068 & 0.00 & 0.052 & 0.00 & -0.018 & 0.01 & -0.008 & 0.60 & -0.029 & 0.11 \\
\hline Intercept & 0.476 & 0.00 & 0.398 & 0.00 & 0.555 & 0.00 & 0.448 & 0.00 & 0.438 & 0.00 & 0.464 & 0.00 \\
\hline
\end{tabular}

\begin{tabular}{|c|c|c|c|c|c|c|c|c|c|c|c|c|}
\hline \multirow{3}{*}{$\begin{array}{c}\text { Panel B } \\
\beta_{\mathrm{s}}\end{array}$} & \multicolumn{6}{|c|}{ Quarterly Data } & \multicolumn{6}{|c|}{ Monthly Data } \\
\hline & \multicolumn{2}{|c|}{$\mathrm{S}$} & \multicolumn{2}{|c|}{$\operatorname{Pr}(\mathrm{F}>\mathrm{A} / \mathrm{z}+)$} & \multicolumn{2}{|c|}{$\operatorname{Pr}(\mathrm{F}<\mathrm{A} / \mathrm{z}-)$} & \multicolumn{2}{|c|}{$\mathrm{S}$} & \multicolumn{2}{|c|}{$\operatorname{Pr}(\mathrm{F}>\mathrm{A} / \mathrm{z}+)$} & \multicolumn{2}{|c|}{$\operatorname{Pr}(\mathrm{F}<\mathrm{A} / \mathrm{z}-)$} \\
\hline & coef & $\begin{array}{c}\text { p- } \\
\text { value }\end{array}$ & coef & $\begin{array}{c}\mathrm{p}- \\
\text { value }\end{array}$ & coef & $\begin{array}{c}\text { p- } \\
\text { value }\end{array}$ & coef & $\begin{array}{c}\text { p- } \\
\text { value }\end{array}$ & coef & $\begin{array}{c}\text { p- } \\
\text { value }\end{array}$ & coef & $\begin{array}{c}\text { p- } \\
\text { value }\end{array}$ \\
\hline $\begin{array}{r}\text { Sent } \\
\text { global }\end{array}$ & -0.019 & 0.07 & 0.028 & 0.00 & -0.040 & 0.00 & -0.025 & 0.01 & 0.069 & 0.00 & -0.081 & 0.00 \\
\hline NEPS & 0.003 & 0.00 & 0.002 & 0.01 & 0.003 & 0.00 & 0.007 & 0.00 & 0.008 & 0.00 & 0.007 & 0.00 \\
\hline HOR & -0.001 & 0.00 & 0.000 & 0.42 & -0.001 & 0.00 & -0.001 & 0.00 & 0.000 & 0.35 & -0.001 & 0.00 \\
\hline NAFF & 0.007 & 0.00 & 0.010 & 0.00 & 0.003 & 0.10 & 0.006 & 0.00 & 0.009 & 0.00 & 0.002 & 0.23 \\
\hline CHES & 0.001 & 0.74 & 0.001 & 0.53 & -0.001 & 0.85 & 0.001 & 0.04 & 0.001 & 0.32 & 0.001 & 0.50 \\
\hline FERR & -0.008 & 0.27 & -0.070 & 0.00 & 0.055 & 0.00 & -0.018 & 0.01 & -0.011 & 0.49 & -0.027 & 0.13 \\
\hline Intercept & 0.466 & 0.00 & 0.449 & 0.00 & 0.499 & 0.00 & 0.434 & 0.00 & 0.471 & 0.00 & 0.475 & 0.00 \\
\hline
\end{tabular}

\begin{tabular}{|c|c|c|c|c|c|c|c|c|c|c|c|c|}
\hline \multirow{3}{*}{$\begin{array}{c}\text { Panel C } \\
B_{\mathrm{s}}\end{array}$} & \multicolumn{6}{|c|}{ Quarterly Data } & \multicolumn{6}{|c|}{ Monthly Data } \\
\hline & \multicolumn{2}{|c|}{$\mathrm{S}$} & \multicolumn{2}{|c|}{$\operatorname{Pr}(\mathrm{F}>\mathrm{A} / \mathrm{z}+)$} & \multicolumn{2}{|c|}{$\operatorname{Pr}(\mathrm{F}<\mathrm{A} / \mathrm{z}-)$} & \multicolumn{2}{|c|}{$\mathrm{S}$} & \multicolumn{2}{|c|}{$\operatorname{Pr}(\mathrm{F}>\mathrm{A} / \mathrm{z}+)$} & \multicolumn{2}{|c|}{$\operatorname{Pr}(\mathrm{F}<\mathrm{A} / \mathrm{z}-)$} \\
\hline & coef & $\begin{array}{c}\mathrm{p}- \\
\text { value }\end{array}$ & coef & $\begin{array}{c}\mathrm{p}- \\
\text { value }\end{array}$ & coef & $\begin{array}{c}\mathrm{p}- \\
\text { value }\end{array}$ & coef & $\begin{array}{c}\mathrm{p}- \\
\text { value }\end{array}$ & coef & $\begin{array}{c}\mathrm{p}- \\
\text { value }\end{array}$ & coef & $\begin{array}{c}\mathrm{p}- \\
\text { value }\end{array}$ \\
\hline $\begin{array}{r}\text { Sent } \\
\text { global }\end{array}$ & -0.007 & 0.03 & 0.025 & 0.00 & -0.034 & 0.00 & -0.009 & 0.06 & 0.033 & 0.00 & -0.034 & 0.00 \\
\hline $\begin{array}{r}\text { Sent loc } \\
\text { Orthog }\end{array}$ & & & & & & & & & c & & & \\
\hline NEPS & 0.004 & 0.00 & 0.002 & 0.01 & 0.003 & 0.00 & 0.007 & 0.00 & 0.008 & 0.00 & 0.007 & 0.00 \\
\hline HOR & -0.001 & 0.00 & 0.000 & 0.47 & -0.001 & 0.00 & -0.001 & 0.00 & 0.000 & 0.34 & -0.001 & 0.00 \\
\hline NAFF & 0.007 & 0.00 & 0.010 & 0.00 & 0.003 & 0.13 & 0.006 & 0.00 & 0.009 & 0.00 & 0.002 & 0.21 \\
\hline CHES & -0.001 & 0.02 & 0.000 & 0.50 & -0.000 & 0.79 & 0.001 & 0.03 & 0.001 & 0.03 & 0.001 & 0.73 \\
\hline FERR & -0.003 & 0.56 & -0.070 & 0.00 & 0.054 & 0.00 & -0.019 & 0.00 & -0.011 & 0.46 & 0.025 & 0.15 \\
\hline Intercept & 0.495 & 0.00 & 0.449 & 0.00 & 0.500 & 0.00 & 0.480 & 0.00 & 0.426 & 0.00 & 0.486 & 0.00 \\
\hline
\end{tabular}


Table 4. Results of regression analysis of firm characteristics on herding. $\mathrm{S}_{\mathrm{i}, \mathrm{t}}$ is the dependent variable that captures the value of the proxy herding statistic for firm i during month t, HVQ (hard-to-value firms,) EVQ (easy-to-value firms), HOR (average age of forecasts used to estimate S), NEPS (number of individual forecasts), NAFF (number of analysts following a firm), CHES (standard deviation of quarterly earnings per share), FERR (average forecast error for each firm-period).The stock characteristics are size (SIZE), volatility (VOL), BTM ratio (BTM) and dividend per share (DPS).

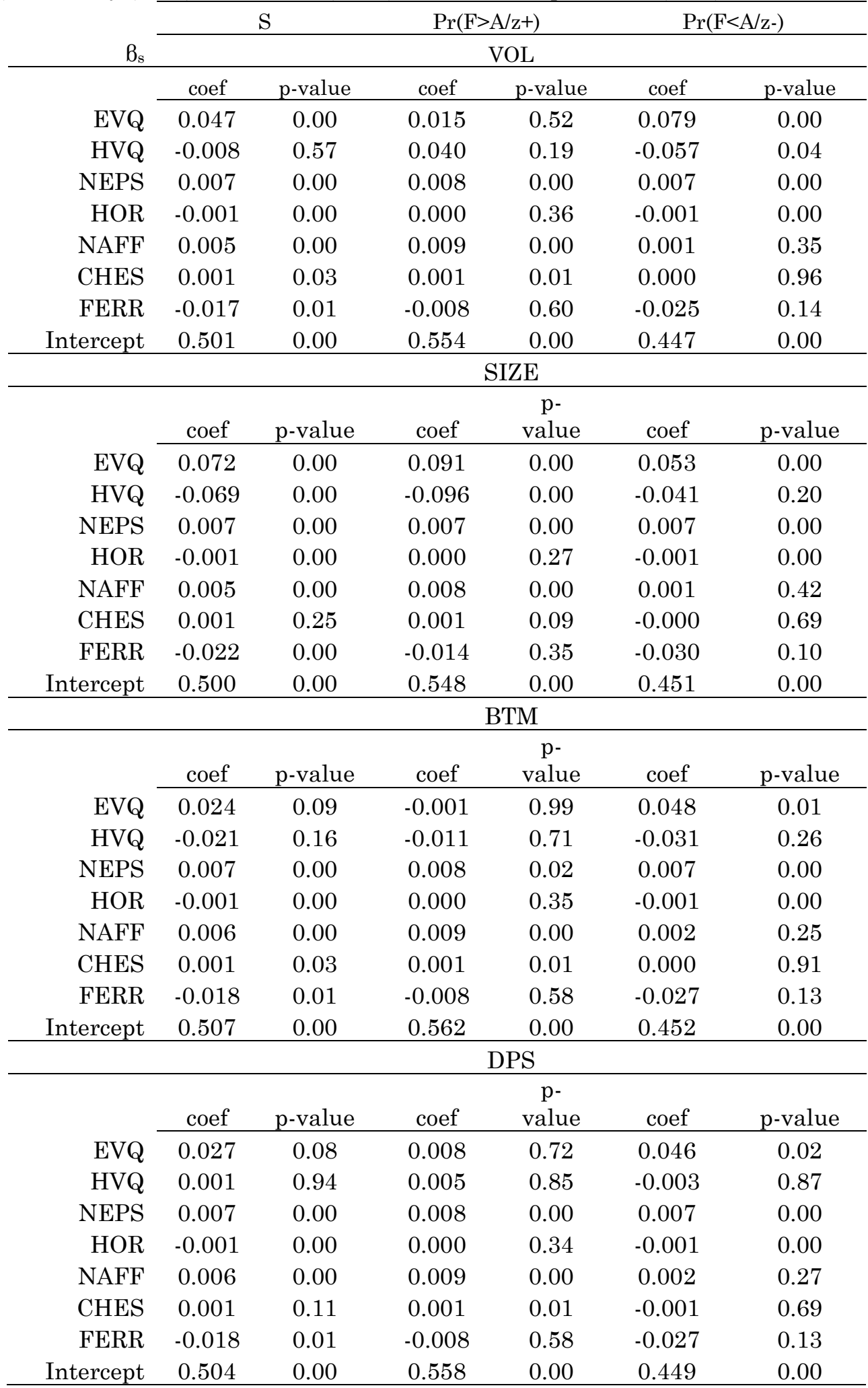


Table 5. Results of regression analysis based on firm characteristics and sentiment simultaneously. $\mathrm{S}_{\mathrm{i}, \mathrm{t}}$ is the dependent variable that captures the value of the proxy herding statistic for firm i during month t, HVQ (hard-to-value firms,) EVQ (easy-to-value firms). The stock characteristics are size (SIZE), volatility (VOL), BTM ratio (BTM) and dividend per share (DPS). Sent is the local investor sentiment. Control variables have been used in the estimation process, although for the sake of clarity they are not included in this table.

\begin{tabular}{|c|c|c|c|c|c|c|c|c|c|c|c|c|}
\hline \multirow{3}{*}{$B_{\mathrm{s}}$} & \multicolumn{4}{|c|}{$\mathrm{S}$} & \multicolumn{4}{|c|}{$\operatorname{Pr}(\mathrm{F}>\mathrm{A} / \mathrm{z}+)$} & \multicolumn{4}{|c|}{$\operatorname{Pr}(\mathrm{F}<\mathrm{A} / \mathrm{z}-)$} \\
\hline & coef & $\begin{array}{c}\mathrm{p}- \\
\text { value }\end{array}$ & coef & $\begin{array}{c}\mathrm{p}- \\
\text { value }\end{array}$ & coef & $\begin{array}{c}\mathrm{p}- \\
\text { value }\end{array}$ & coef & $\begin{array}{c}\mathrm{p}- \\
\text { value }\end{array}$ & coef & $\begin{array}{c}\mathrm{p}- \\
\text { value }\end{array}$ & coef & $\begin{array}{c}\mathrm{p}- \\
\text { value }\end{array}$ \\
\hline & \multicolumn{12}{|c|}{ VOL } \\
\hline Sent & -0.028 & 0.00 & -0.026 & 0.00 & 0.068 & 0.00 & 0.032 & 0.00 & -0.055 & 0.00 & -0.072 & 0.00 \\
\hline EVQ & 0.047 & 0.00 & 0.047 & 0.00 & 0.015 & 0.51 & 0.013 & 0.57 & 0.079 & 0.00 & 0.079 & 0.00 \\
\hline HVQ & -0.006 & 0.64 & -0.007 & 0.63 & 0.034 & 0.27 & 0.031 & 0.33 & -0.054 & 0.05 & -0.053 & 0.06 \\
\hline EVQ*Sent & & & -0.001 & 0.90 & & & 0.001 & 0.97 & & & -0.002 & 0.80 \\
\hline \multirow[t]{2}{*}{ HVQ*Sent } & & & -0.006 & 0.30 & & & -0.012 & 0.21 & & & 0.006 & 0.61 \\
\hline & \multicolumn{12}{|c|}{ SIZE } \\
\hline Sent & -0.026 & 0.00 & -0.022 & 0.03 & 0.066 & 0.00 & 0.055 & 0.00 & -0.056 & 0.00 & -0.045 & 0.00 \\
\hline EVQ & 0.072 & 0.00 & 0.072 & 0.00 & 0.092 & 0.00 & 0.082 & 0.00 & 0.052 & 0.00 & 0.052 & 0.00 \\
\hline HVQ & -0.068 & 0.00 & -0.069 & 0.00 & -0.099 & 0.00 & -0.101 & 0.00 & -0.040 & 0.22 & -0.039 & 0.23 \\
\hline EVQ*Sent & & & -0.006 & 0.17 & & & 0.004 & 0.73 & & & -0.016 & 0.12 \\
\hline \multirow[t]{2}{*}{$\mathrm{HVQ}^{*}$ Sent } & & & -0.016 & 0.01 & & & -0.018 & 0.13 & & & -0.013 & 0.29 \\
\hline & \multicolumn{12}{|c|}{ BTM } \\
\hline Sent & -0.031 & 0.00 & -0.029 & 0.00 & 0.068 & 0.00 & 0.073 & 0.00 & -0.055 & 0.00 & -0.058 & 0.00 \\
\hline EVQ & 0.024 & 0.09 & 0.024 & 0.09 & -0.001 & 0.97 & -0.001 & 0.96 & 0.049 & 0.01 & 0.048 & 0.01 \\
\hline HVQ & -0.021 & 0.16 & -0.021 & 0.16 & -0.011 & 0.71 & -0.010 & 0.72 & -0.031 & 0.26 & -0.032 & 0.25 \\
\hline EVQ*Sent & & & -0.005 & 0.33 & & & -0.016 & 0.18 & & & 0.005 & 0.57 \\
\hline \multirow[t]{2}{*}{ HVQ*Sent } & & & 0.002 & 0.96 & & & -0.017 & 0.13 & & & 0.016 & 0.20 \\
\hline & \multicolumn{12}{|c|}{ DPS } \\
\hline Sent & -0.028 & 0.00 & -0.027 & 0.00 & 0.068 & 0.00 & 0.066 & 0.00 & -0.056 & 0.00 & -0.052 & 0.00 \\
\hline EVQ & 0.027 & 0.08 & 0.027 & 0.08 & 0.011 & 0.65 & 0.011 & 0.65 & 0.045 & 0.02 & 0.045 & 0.02 \\
\hline HVQ & 0.001 & 0.89 & 0.002 & 0.89 & 0.001 & 0.95 & 0.001 & 0.95 & -0.001 & 0.94 & -0.001 & 0.94 \\
\hline EVQ*Sent & & & -0.002 & 0.57 & & & -0.002 & 0.88 & & & -0.004 & 0.69 \\
\hline HVQ*Sent & & & -0.001 & 0.84 & & & 0.007 & 0.47 & & & -0.009 & 0.36 \\
\hline
\end{tabular}

